\title{
Aus der Sicht eines ehemaligen internationalen Kinderstars...
}

\author{
Piero Lercher im exklusiven Gespräch mit Jermaine Jackson dem US-Sänger und \\ ehemaligen Kinderstar der Soulbands The Jackson Brothers und The Jackson Five
}

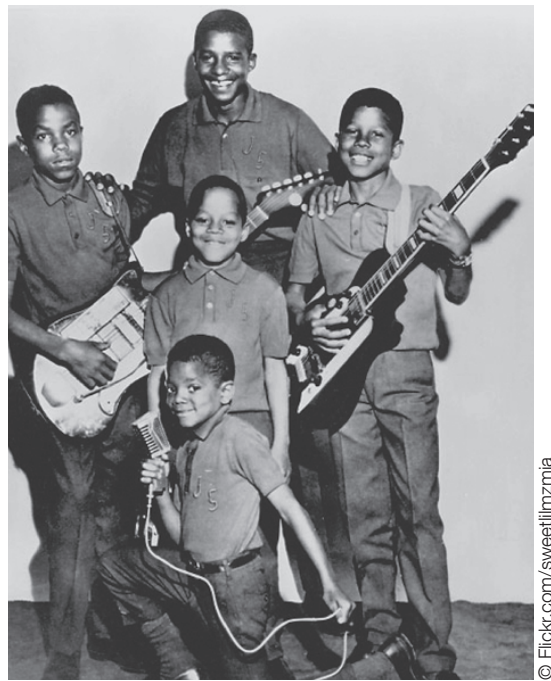

The Jackson Brothers 1965 (Jermaine ganz re)

Allein The Jackson Five haben bis zu ihrer Auflösung im Jahr 1989 über 100 Millionen Schallplatten verkauft. Bis heute werden mit ihren Songs, CoverVersionen, Compilations und sonstigen Vermarktungsrechten jährlich rund 50 Millionen Dollar an Tantiemen lukriert. Jermaine Jackson ist vom Kinderstar zu einer Persönlichkeit herangereift, die sich für karitative Projekte und insbesondere für Waisenkinder einsetzt. Er hat viele spektakuläre Konzerte erlebt, sein wohl schwierigster Auftritt war jedoch am 25. Juni 2009, als er im Rahmen einer Pressekonferenz im Ronald Reagan UCLA Medical Center in Los Angeles der internationalen Medienwelt den Tod seines jüngeren Bruders Michael bekanntgeben musste.

Viele Eltern wünschen sich Wunderkinder oder Kinderstars. Wie stehen Sie dazu als Person, die selbst einen Teil der Kindheit ,opfern“ musste und welche Schlüsse ziehen Sie daraus für die Erziehung Ihrer Kinder?

JERMAINE JACKSON: Wir sind mit dem Bedürfnis aufgewachsen, mit den Kindern von der anderen Straßenseite zu spielen. Wir wollten Feuerwehrmänner werden oder Besitzer eines Eissalons,

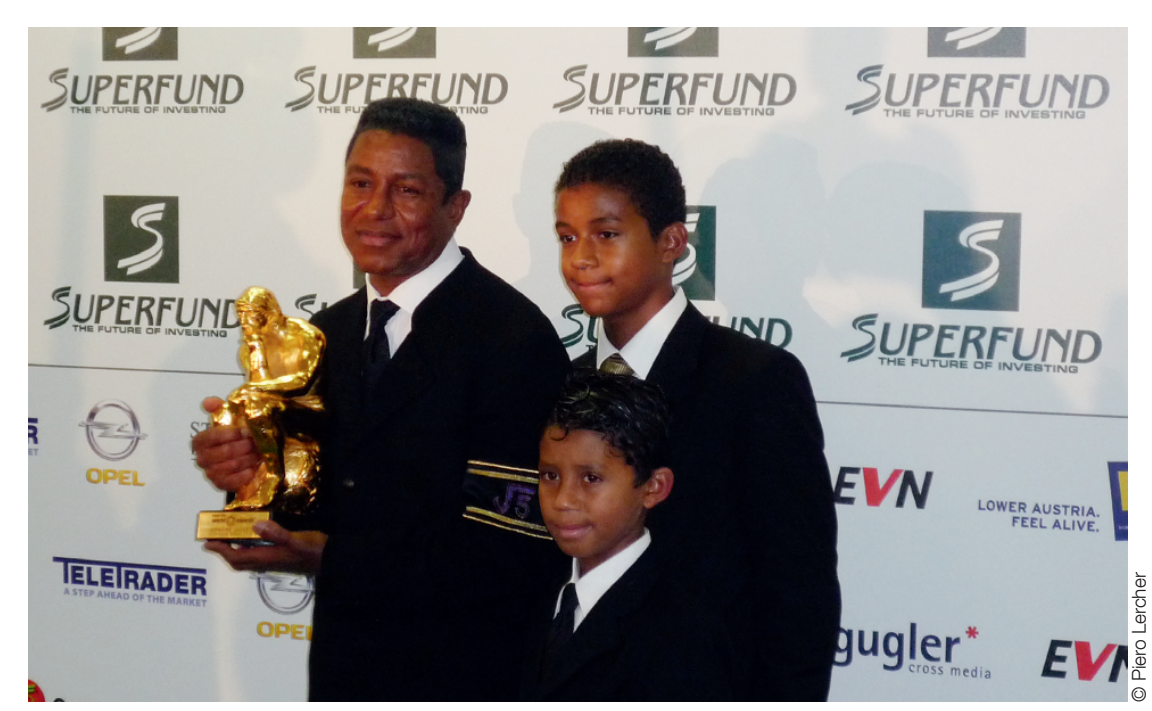

Jermaine Jackson und seine Söhne Jaffar und Jermajesty mit dem „Save The World Award 2009“ aber mein Vater erkannte unser Gesangs-Talent und verbrachte sehr viel Zeit mit uns. Der Rest ist Geschichte...

Ich habe selbst mehrere Kinder und finde es sehr wichtig sie so zu prägen und $\mathrm{zu}$ formen, damit sie so werden, wie wir es uns vorstellen. Es fängt dabei bereits zu Hause an - wenn sie zu Hause nicht auf deine Ratschläge hören, dann werden sie beispielsweise nicht erfolgreich in der Schule sein. Meine zwei jüngsten Söhne hören das jetzt gerade weil ich ihnen meine Erfahrungen mitteile - sie erfahren, wie man zuhört und beobachtet, damit sie, wenn sie Feuerwehrmänner werden oder ins Musikgeschäft gehen oder Wissenschaftler werden, wissen, wie man zuhört, beobachtet und Anweisungen annimmt, damit sie letztendlich dadurch den gewünschten Erfolg erreichen.

Welche Botschaft möchten Sie unseren Lesern/innen mitgeben? handelt werden, denn sie regieren die Welt von morgen.

Das Interview führte Dr. Piero Lercher am 23.07.2009 in Wien.Jermaine Jackson kam zum ersten Mal nach Europa, gemeinsam mit seiner aktuellen Ehefrau Halima Rashid und den Söhnen Jaffar (13) und Jermajesty (9). Er nahm am 24.07.2009 anlässlich einer werk Zwentendorf den "Save The World Award" im Namen seines kürzlich zuvor verstorbenen Bruders Michael entgegen, der posthum für sein Engagemen für eine bessere Welt gewürdigt wurde (siehe auch: www.worldawards.com)
JACKSON: Kinder müssen stets gut beGala im niemals in Betrieb gegangenen AtomkraftGerk Z wentendorf den Save The World Award" im

\section{Zur Person}

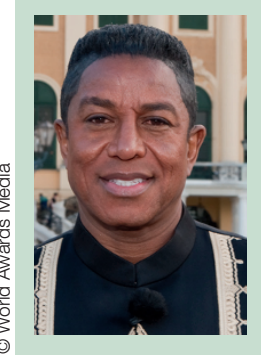

Jermaine La Jaune Jackson

(geboren am Dezember 1954) ist ein US-amerikanischer Sänger Bassist, Komponist und Mitglied der ehemaligen „Kinder-Soulbands" The Jackson Brothers und The Jackson Five. Nach Michael und Janet machte er die dritterfolgreichste Solokarriere der Jackson-Geschwister. Im Jahr 1984 hatte er mit dem im Duett mit Pia Zadora eingesungenen Titel „When The Rain Begins To Fall" einen weltweit bekannten Nummer-1-Hit. Er ist Vater von sieben Söhnen und zwei Töchtern. 